of perhaps the best known and most trustworthy of our British manufacturing chemists, and was dispensed by a local firm with a very high reputation for accuracy.

The patient, A.B., aet. $5 \frac{1}{2}$ years, suffering from hypermetropic astigmatism, had, two years earlier, had her refraction determined after atropinization. On this occasion, a solution of sulphate of atropin, gr. 4 to $\xi 1$, had been dropped into each eye twice daily for three consecutive days. There was then no symptom whatever of belladonna poisoning, so that it may safely be assumed that the patient had no undue susceptibility to atropin.

On her return two years later for re-examination, it was considered sufficient to use homatropin. A drop of the solution, 4 gr. to 31 , was instilled into each eye, and the child was allowed to go out with her mother to visit some friends in the immediate neighbourhood, with instructions to return in an hour. When she did return -two hours later-the cause of the delay was sufficiently obvious. The child was in a condition of intense mental excitement, laughing, talking incoherently, and with hallucinations of vision. She also complained of dryness of the mouth. As examination was out of the question she was sent home. The excitement continued without abatement until 3 o'clock in the following morning (i.e., ten hours), when she fell asleep. On waking five or six hours later, her condition had become normal.

The same solution has been frequently used since. In the majority of cases, the patient has been conscious of no unusual general effects. In one or two, however, there has been produced a slight sensation of giddiness together with some dryness of the mouth. This would suggest that impurity of the drug, may, in some degree, account for the facts of the case.

\title{
A CASE OF CONGESTIVE GLAUCOMA AFTER THE USE OF HOMATROPIN AND ESERIN
}

\author{
BY \\ H. M. Desai, D.Ch.O. (Liverpool), \\ SURGICAL OFFICER IN CHARGE, EYE INFIRMARY, SUNDERLAND.
}

MRS. S. B., aged 48 years, attended the Sunderland Eye Infirmary on May 3, 1918, to have her eyes tested for distant glasses. Had glasses for near work in October, 1917, and they were quite satisfactory. $\mathrm{V} .=6 / 18$. Tension, as tested by the fingers, was normal and pupil reaction was good. Mydriasis was produced by homatropin 1 per cent. and a drop of eserin sulph. 1 per cent. was instilled in each eye before the patient left. Refraction $+4.5 \mathrm{D}$. in 
each eye. V. $=6 / 6$ in both with glasses. The patient returned on Monday, May 6, complaining that she had severe pain and loss of sight in the right eye since Saturday. She presented all the symptoms of congestive glaucoma-dilated immobile pupil, very shallow anterior chamber, and steamy cornea; tension $45 \mathrm{~mm}$. of $\mathrm{Hg}$ with Schiötz' tonometer. V.=light perception. Fundus could not be seen. After repeated instillations of eserin the pupil was distinctly contracted and, as the patient would not consent to an immediate operation, more eserin was given for home use.

Wednesday, May 8. Eye quieter. T. $=30 \mathrm{~mm}$. of $\mathrm{Hg}$. V.= fingers at a foot. Iridectomy was performed the same day. Tension remained subnormal for two days then rose again and was $25 \mathrm{~mm}$. of $\mathrm{Hg}$ on May 12. As it did not diminish under eserin, Elliot's operation of-sclero-corneal trephining was done on May 15 with satisfactory and so far permanent result. Tension was $15 \mathrm{~mm}$. of $\mathrm{Hg}$ on the tenth day after the operation and has remained normal ever since. $\mathrm{V} .=6 / 36$. With glasses $+2.5 \mathrm{D}$. sphere $\mathrm{V} .=6 / 18$. Refraction of the eye has been increased by 2 dioptres (26-6-18).

The chief points of interest in this case are:

(1) Onset of congestive glaucoma after use of homatropin, in spite of the fact that eserin had been used to counteract its effect, thus showing that homatropin had continued to act after the effect of eserin had passed away.

(2) Failure of iridectomy to relieve hypertension. This may be due to faulty technique, but the writer has since found Elliot's operation easier, no way more painful, and more satisfactory than iridectomy in cases of congestive glaucoma.

(3) Increase of refraction due to permanent stretching of the zonula and pushing forward of the lens. Refraction was still the same in December as it was on June 26, 1918.

\section{ANNUAL CONGRESS OF THE OPHTHALMOLOGICAL SOCIETY OF THE UNITED KINGDOM}

THE Sixth Annual Congress of the Ophthalmological Society of the United Kingdom was held under the Presidency of Mr. J. B. Story on Thursday, Friday, and Saturday, May 1, 2, 3, 1919.

The Congress was largely attended and was very successful, many papers of unusual interest being communicated.

The President opened the Congress, on May 1st, at the Royal Society of Medicine, and welcomed the members and visitors with a few well-chosen words. Sir Anderson Critchett, Bt., K.C.V.O., 